Neubauer, Andreas B.; Dirk, Judith; Schmiedek, Florian

\title{
Momentary working memory performance is coupled with different dimensions of affect for different children: A mixture model analysis of ambulatory assessment data.
}

formal und inhaltlich überarbeitete Version der Originalveröffentlichung in:

formally and content revised edition of the original source in:

Developmental psychology 55 (2019) 4, S. 754-766

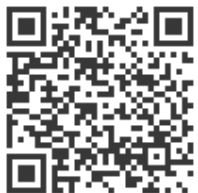

Bitte verwenden Sie in der Quellenangabe folgende URN oder DOI /

Please use the following URN or DOI for reference:

urn:nbn:de:0111-pedocs-181292

$10.25656 / 01: 18129$

https://nbn-resolving.org/urn:nbn:de:0111-pedocs-181292

https://doi.org/10.25656/01:18129

\section{Nutzungsbedingungen}

Gewährt wird ein nicht exklusives, nicht übertragbares, persönliches und beschränktes Recht auf Nutzung dieses Dokuments. Dieses Dokument ist ausschließlich für den persönlichen, nicht-kommerziellen Gebrauch bestimmt. Die Nutzung stellt keine Übertragung des Eigentumsrechts an diesem Dokument dar und gilt vorbehaltlich der folgenden Einschränkungen Auf sämtlichen Kopien dieses Dokuments müssen alle Urheberrechtshinweise und sonstigen Hinweise auf gesetzlichen Schutz beibehalten werden. Sie dürfen dieses Dokument nicht in irgendeiner Weise abändern, noch dürfen Sie dieses Dokument für öffentliche oder kommerzielle Zwecke vervielfältigen, öffentlich ausstellen, aufführen, vertreiben oder anderweitig nutzen.

Mit der Verwendung dieses Dokuments erkennen Sie die Nutzungsbedingungen an.

\section{Terms of use}

We grant a non-exclusive, non-transferable, individual and limited right to using this document.

This document is solely intended for your personal, non-commercial use. Use of this document does not include any transfer of property rights and it is conditional to the following limitations: All of the copies of this documents must retain all copyright information and other information regarding legal protection. You are not allowed to alter this document in any way, to copy it for public or commercial purposes, to exhibit the document in public, to perform, distribute or otherwise use the document in public.

By using this particular document, you accept the above-stated conditions of use.

\section{Kontakt / Contact:}

peDOCS

DIPF | Leibniz-Institut für Bildungsforschung und Bildungsinformation Informationszentrum (IZ) Bildung

E-Mail:pedocs@dipf.de

Internet: www.pedocs.de

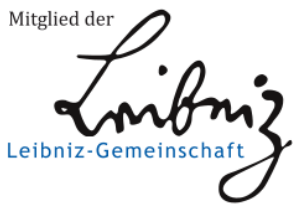


CAmerican Psychological Association, 2019. This paper is not the copy of record and may not exactly replicate the authoritative document published in the APA journal. Please do not copy or cite without author's permission. The final article is available, upon publication, at: https://doi.org/10.1037/dev0000668 
Momentary Working Memory Performance is Coupled with Different Dimensions of Affect for Different Children: A Mixture Model Analysis of Ambulatory Assessment Data Andreas B. Neubauer ${ }^{1,2}$, Judith Dirk ${ }^{1,2}$, \& Florian Schmiedek ${ }^{1,2,3}$

${ }^{1}$ German Institute for International Educational Research (DIPF), Frankfurt am Main, Germany

${ }^{2}$ Center for Research on Individual Development and Adaptive Education of Children at Risk (IDeA), Frankfurt am Main, Germany

${ }^{3}$ Goethe University, Frankfurt am Main, Germany

\section{Author Note}

Andreas B. Neubauer, Department of Education and Human Development, German Institute for International Educational Research (DIPF), Frankfurt am Main, Germany and Center for Research on Individual Development and Adaptive Education of Children at Risk (IDeA), Frankfurt am Main, Germany; Judith Dirk, Department of Education and Human Development, German Institute for International Educational Research (DIPF), Frankfurt am Main, Germany and Center for Research on Individual Development and Adaptive Education of Children at Risk (IDeA), Frankfurt am Main, Germany; Florian Schmiedek, Department of Education and Human Development, German Institute for International Educational Research (DIPF), Frankfurt am Main, Germany, Center for Research on Individual Development and Adaptive Education of Children at Risk (IDeA), Frankfurt am Main, Germany, and Goethe University, Frankfurt am Main, Germany. 
Correspondence concerning this article should be addressed to Andreas B. Neubauer, Education and Human Development, German Institute for International Educational Research (DIPF), Frankfurt am Main, Germany. E-Mail: neubauer.andreas@dipf.de

\section{Acknowledgments}

This research was part of the FLUX project at the IDeA-Center in Frankfurt am Main, Germany, which was funded by the Hessian Initiative for the Development of Scientific and Economic Excellence (LOEWE). We thank Heiko Rölke and the Technology Based Assessment Group at the DIPF for developing and providing the software to assess children's performance and experiences via smartphones. We owe special thanks to Verena Diel, Tanja Könen, Jan Kühnhausen, Anja Leonhardt, Philipp Wiesemann, and a team of highly committed student assistants for their important roles in conducting the FLUX project. FS and ABN further acknowledge support from the Jacobs Foundation (grant number 2016-1245-00).

C 2018, American Psychological Association. This paper is not the copy of record and may not exactly replicate the final, authoritative version of the article. Please do not copy or cite without authors' permission. The final article will be available, upon publication, via its DOI: $10.1037 / \operatorname{dev} 0000668$ 


\begin{abstract}
Elementary school children's working memory performance (WMP) fluctuates from moment to moment and day to day, yet the underlying mechanisms are not well understood. In the present study, affective states were investigated as predictors of these fluctuations. Interindividual differences in the intra-individual affect-WMP associations were expected, and their structure was explored. One hundred nine children (8-11 years) were investigated in an ambulatory assessment. Affective states (positive affect, negative affect, activation, deactivation) and WMP were assessed three times daily for up to 31 consecutive days. In the whole sample, WMP was lower at occasions with higher negative affect or deactivation, while there was no overall effect of positive affect or activation. Results of a mixture model analysis revealed meaningful heterogeneity in these effects: Approximately half of the children showed comparably weaker effects of affect on WMP, while the other three groups showed (a) comparably stronger negative effects of negative affect and deactivation; (b) a comparably stronger positive effect of activation; or (c) comparably stronger negative effects of negative affect and deactivation and stronger positive effects of positive affect and activation. Findings emphasize the importance of explicitly considering inter-individual differences in intra-individual associations. They are discussed in the context of current frameworks of inter-individual differences in environmental sensitivity.
\end{abstract}

Keywords: ambulatory assessment; within-person processes; working memory; differential susceptibility; environmental sensitivity; intra-individual variability 


\section{Momentary Working Memory Performance is Coupled with Different Dimensions of}

\section{Affect for Different Children: A Mixture Model Analysis of Ambulatory Assessment}

\section{Data}

Executive functions (EF) describe a set of cognitive processes involved in everyday tasks that require top-down control (Diamond, 2013). Inter-individual differences in EF in childhood have been related to positive adjustment throughout the human life span, with better EF associated with better achievement in school (Gathercole, Pickering, Knight, \& Stegmann, 2004) as well as various indicators of psychological adjustment up to 20 years later (e.g., physical health and financial situation; Moffitt et al., 2011). Importantly, these studies conceptualized EF as a more or less stable, person-level (trait) variable, while intra-individual (day-to-day or moment-to-moment) fluctuations of EF components have only recently received some attention in research with children and adolescents (Dirk \& Schmiedek, 2016; Riediger, Wrzus, Schmiedek, Wagner, \& Lindenberger, 2011). In the present work, we examine momentary affective experiences as predictors of intra-individual fluctuations in working memory performance (WMP). WMP requires simultaneous storage and processing of several elements and thereby requires and encompasses central components of EF (Miyake et al., 2000). Investigating the antecedents of ups-and-downs in cognitive functioning in children's daily lives allows for better understanding the processes that lead to better vs. worse cognitive functioning in everyday contexts, and thereby potentially opens up possibilities to improve WMP via interventions targeting these predictors.

Prior research has shown that intra-individual fluctuations in sleep (Könen, Dirk, \& Schmiedek, 2015) and perceived disturbance (Dirk \& Schmiedek, 2017) are systematically "coupled" with intra-individual fluctuations in WMP in elementary school children. In the present work, we focus on current affective states as potential predictors of WMP. Specifically, our focus lies on inter-individual differences in intra-individual couplings of 
affective experiences and WMP in elementary school children. That is, we investigate if children differ in the degree to which their WMP is associated with their current affective state. The next sections will be organized as following: First, we will summarize prior research that investigated the association between affective states and EF / WMP. We will primarily focus either on research with children or on research that has specifically investigated intra-individual associations of these two constructs. Next, we will introduce environmental sensitivity (Pluess, 2015) as a framework to investigate the structure of interindividual differences in these intra-individual couplings. We then present findings from an ambulatory assessment study with 109 elementary school children.

\section{Associations Between Affect and WMP}

Associations between affective states and cognitive functioning have received substantial attention in the literature. Due to the scarcity of studies specifically targeting WMP (especially in children) we provide a non-exhaustive overview of studies investigating either WMP or EF components. Negative affect (NA) has often been negatively associated with cognitive performance (Ellis, Moore, Varner, A. Ottaway, \& S. Becker, 1997), but the processes underlying this association remain largely unknown. One explanation proposed is that NA interferes with resources available to work on cognitive tasks, and is therefore related to poorer EF (Ashcraft \& Kirk, 2001; Ellis \& Ashbrook, 1988; Ilkowska \& Engle, 2010). Other mediating mechanisms have been proposed as well, such as decreases in serotonin (Mitchell \& Phillips, 2007) or motivational decrements (Brose, Schmiedek, Lövdén, \& Lindenberger, 2012). Furthermore, the hypothalamic-pituitary-adrenal (HPA) axis might also play an important role in this association, since previous research found that its end product (cortisol) can have detrimental effects on cognitive performance (Lupien, Gillin, \& Hauger, 1999). While the proposed mechanisms for the effect of NA on cognitive performance concur in predicting a negative association, the role of positive affect (PA) for EF is less clear. Some 
(Ashby, Isen, \& Turken, 1999) suggest that mild levels of PA should be associated with slightly elevated dopamine levels and — as a consequence—with better EF. Others argue that elevated PA occupies cognitive resources as well and should therefore be associated with diminished performance in EF tasks (Mitchell \& Phillips, 2007).

Previous research points toward a deteriorating effect of NA on EF (Patel et al., 2016), while findings regarding the effects of PA are more inconsistent with some reporting a positive effect on EF (Palmiero, Nori, Rogolino, D'Amico, \& Piccardi, 2015; Yang, Yang, \& Isen, 2013), and others reporting a negative effect (Martin \& Kerns, 2011). Most of previous research has, however, targeted these associations in adult samples and research in children is comparatively sparse. Investigating the dynamics of EF / WMP in this population would, however, be highly important because the development and maturation of EF and WMP is ongoing from birth well into the teen years (Diamond, 2013; Gathercole et al., 2004), and a better understanding of the processes involved in this developmental phase could hint towards promising interventions and policy implications.

Two experimental studies revealed similar findings in children as studies among adults. In one study on children between 9 and 12 years (Fartoukh, Chanquoy, \& Piolat, 2014), a negative mood induction lead to decreasing performance in a letter-number sequencing task (an indicator of WMP), while no effect of a positive mood induction could be observed (relative to a neutral control condition). Similarly, Pnevmatikos and Trikkaliotis (2013) showed that an anxiety induction led to poorer inhibitory control (a facet of EF) in children between 8 and 12 years. That is, these studies suggest that negative affect is associated with poorer EF in children, while no effect for PA could be observed.

The vast amount of the aforementioned studies has exclusively focused on betweenperson associations of affect and EF / WMP. While this approach is certainly informative when the core focus lies on determining inter-individual differences, it cannot uncover intra- 
individual processes, unless unrealistic assumptions are being made (Molenaar, 2004).

Crucially, models explaining the associations between affect and EF such as the resource allocation model (Ellis \& Ashbrook, 1988) target effects that unfold within individuals over time. Taking a within-person perspective with regard to both study design and data analysis is paramount to investigate these intra-individual processes (Hamaker, 2012). A few studies have targeted intra-individual effects of affective states on WMP, and all of these have been conducted with adults or adolescents. With regard to NA, some studies revealed a negative intra-individual effect on WMP (Brose et al., 2012; Riediger et al., 2011), while others (Sliwinski, Smyth, Hofer, \& Stawski, 2006; Stumm, 2016) did not find significant intraindividual associations. Previous findings regarding the intra-individual effect of PA on WMP are also mixed with some (Brose, Lövdén, \& Schmiedek, 2014) reporting a positive association, others a quadratic association, indicating elevated performance at medium levels of PA (Riediger et al., 2011), or no association (Stumm, 2016).

Part of the inconsistency in previous research might be attributed to the existence of meaningful inter-individual differences in the intra-individual coupling of affect and WMP: While there may be some individuals who exhibit meaningful intra-individual couplings between PA / NA and WMP, others might not. Aggregating across individuals could therefore result in a small coupling which could not be detected in these studies because it was masked by inter-individual differences. In the present study, we specifically target these interindividual differences in the intra-individual affect-WMP couplings in children. We now introduce the theoretical framework of environmental sensitivity (ES), which we utilize to better understand the structure of inter-individual differences in the intra-individual affectWMP couplings in elementary school children.

\section{Environmental Sensitivity and Inter-Individual Differences in Affect-WMP Couplings}


The environmental sensitivity framework (Pluess, 2015) considers inter-individual differences in environmental sensitivity as the core determinant of inter-individual differences in reactivity that is, the degree to which current experiences affect physiological, psychological, and behavioral outcomes. According to this view, individuals differ in their ability to register and process external stimuli (=environmental sensitivity), and these differences are associated with inter-individual differences in the degree to which they are affected by their environment (=reactivity). This framework is intended as an integration of various related theoretical accounts. Among others, these include differential susceptibility theory (Belsky \& Pluess, 2009), vantage sensitivity (Pluess \& Belsky, 2013), the diathesisstress model (Zuckerman, 1999), the biological sensitivity to context model (Boyce \& Ellis, 2005), and the adaptive calibration model (Del Giudice, Ellis, \& Shirtcliff, 2011). In a nutshell, all of these accounts aim to explain inter-individual differences in the effects of environmental inputs on physiological, psychological, and behavioral outcomes. They differ, for example, in whether they focus on the effects of positive (VS) or negative environmental inputs (DS), or both (DST; BSC; ACM), as well as in the origins of these differences (genetic vs. environmental) and their postulated mechanisms (Ellis, Boyce, Belsky, BakermansKranenburg, \& van IJzendoorn, 2011; Pluess, 2015). On the most general level, however, they all converge on the prediction that individuals differ in the degree to which physiological, psychological, and behavioral outcomes are affected by environmental conditions.

Subsuming these prior accounts in the ES framework, Pluess (2015) identified four (mutually exclusive) sensitivity types: low sensitivity individuals are characterized by attenuated responses to environmental inputs. That is, these individuals are barely affected by either positive or negative environmental conditions. A second group, referred to as vulnerability group, is hypothesized to respond particularly strongly to negative 
environments. Hence, these individuals can be characterized as vulnerable for the impact of negative environmental effects (sensu a diathesis stress model; Zuckerman, 1999), while they do not necessarily exhibit a pronounced reaction to positive environmental conditions. The third group, which Pluess (2015) called vantage sensitivity group, shows the reversed pattern with enhanced effects specifically of positive environments. Vantage sensitivity is defined as "the general proclivity of an individual to benefit from positive and presumptively well-beingand competence-promoting features of the environment" (Pluess \& Belsky, 2013), and can therefore be seen as a tendency to profit from positive environmental conditions. The fourth group, referred to as general sensitivity, combines elements of the vulnerability group and the vantage sensitivity group: These individuals are strongly affected by both positive and negative environmental inputs. Hence, general sensitivity is close to the concept of differential susceptibility which has been defined as the proclivity to be affected by both adverse and supportive environmental conditions in a "for-better-and-for-worse" manner (Belsky \& Pluess, 2009).

There has been a vast amount of research investigating differences in the effects of environmental conditions, most of which has targeted questions related to human development, in particular development in childhood. Almost exclusively, this research has measured environmental conditions more or less directly (e.g., as parenting quality, physical abuse, socioeconomic status, experimentally induced stress) and has targeted a plethora of outcomes (e.g., academic achievement, attachment style, inhibitory control; see (Belsky \& Pluess, 2009). In the present work, we do not measure positive or negative environmental conditions and examine their differential effects on WMP or affect. Thus, we do not test predictions directly derived from the ES framework. We rather utilize central concepts of this account to examine inter-individual differences in the intra-individual coupling of affect and WMP in children. 
How can the framework of ES, which targets inter-individual differences in reactivity to the environment, inform hypotheses about the structure of inter-individual differences in the intra-individual affect-WMP couplings in children? Conceptually, environmental influences on both affect and WMP can be expected. That is, we can understand both affect and WMP as outcomes of a common cause: environmental input. Further, we can understand both of these variables as outcomes in the ES framework. For example, children in the general sensitivity group will be more strongly affected by environmental inputs (both positive and negative) in their affect and their WMP compared to children in the low sensitivity group. Assuming that differences between children in the effect of environment on affect are related to the same cause (e.g., the same genetic predispositions) and of the same size as differences in the effect of environment on $\mathrm{WMP}^{1}$, children in the general sensitivity group will show larger affect-WMP couplings compared to children in the low sensitivity group. Hence, under these conditions inter-individual differences in affect-WMP couplings can be interpreted as indicators of differences in ES.

\section{The Present Study}

The aim of the present study was to investigate intra-individual couplings of current affective states and WMP in elementary school children's everyday lives using ambulatory assessment (Trull \& Ebner-Priemer, 2013). Previous research investigating intra-individual fluctuations in affect among elementary school children showed that children of this age report affect in a differentiated fashion. Specifically, Leonhardt, Könen, Dirk, and Schmiedek (2016) demonstrated that a six-factor model describing the three affect dimensions valence, energetic arousal, and tense arousal best described the affective experiences reported in a sample from this population. As discussed by Leonhardt et al. (2016), this three-dimensional

\footnotetext{
${ }^{1}$ We note that, according to Pluess (2015), so far "it remains to be determined whether an individual's environmental sensitivity varies across different domains of functioning (e.g., cognitive, emotional, social) or whether differences in sensitivity affect all domains equally" (p.142). For the interpretation of our findings in light of the ES framework, we assume the latter.
} 
affect space concurs with the three-dimensional model of affect by Steyer, Schwenkmezger, Notz, and Eid (1994) and can be related to alternative models of affect such as the two-factor model (Watson \& Tellegen, 1985) and the pleasure-arousal model (Russell \& Barrett, 1999). In the present study, we assessed two of these three dimensions of affective experiencevalence and energetic arousal—by two scales each: Positive affect (PA) and negative affect (NA) represented the two poles of the valence dimension, activation and deactivation represented the two poles of the energetic arousal dimension.

Based on previous studies investigating the within-person effects of NA with cognitive functioning, we hypothesized that indicators of negative affectivity (NA; deactivation) would show a negative within-person association with WMP. Predictions regarding the effects of positive affectivity (PA; activation) were less clear, given the inconsistency in previous research. However, we expected that everyday experiences in our sample would —in many cases — not exceed mild levels of elevated PA, yielding a positive association between positive affective sates and WMP.

Given the somewhat heterogeneous findings in previous studies, we further expected that there would be meaningful inter-individual differences in the intra-individual couplings of all affect indicators with WMP. To better understand these differences, we utilized central ideas from the ES framework. This framework allows deriving the expectation that these differences might be structured into four distinct groups. Specifically, there should be one group of children who are virtually unaffected by affective experiences in their cognitive performance (low sensitivity group). A second group of children is expected to show strong negative effects of negative affective experiences (vulnerability group), while a third group should exhibit pronounced positive effects of positive affective experiences (vantage sensitivity group). Finally, a fourth group is expected that is strongly affected by both positive and negative affective experiences (general sensitivity group). 


\section{Method}

The present study comprised an ambulatory assessment (AA) phase during which children repeatedly worked on cognitive tasks and reported on potential covariates of their cognitive performance. Before and after the AA, extensive pre- and post-test measures were obtained in a classroom setting. The focus of the present work is on the AA phase.

\section{Participants}

The sample comprised 110 children that attended the third $(n=50)$ and fourth grade $(n$ $=60)$, respectively, of an elementary school. The present research is conducted on an already existing data set (Dirk \& Schmiedek, 2016). Hence, sample size was not planned with regard to the specific aims of the present study. One child was discarded for the analyses because he did not provide any concurrent measures of WMP and affective experiences at the same measurement occasion. The analyses are therefore based on the remaining 109 children (45 girls; 8-11 years; $\left.M_{\text {age }}=9.88, S D_{\text {age }}=0.61\right)$. We chose to include only children of Grades 3 and 4 (but not younger) because children participating in this study needed to possess elementary reading and arithmetic skills in order to understand and perform the cognitive tasks. Notably, a recent review on ecological momentary assessment (EMA) in children and adolescents concluded that self-report EMA studies are feasible with children of seven years or older, but it is unclear whether they can be used with younger children (Heron, Everhart, McHale, \& Smyth, 2017). Both children and their parents provided informed consent. Participation was voluntary and could be terminated at any point during the study. Children and parents received money or a gift certificate as remuneration.

\section{Procedure}

The study started with 4.5 hours of training and pretesting, distributed across six school lessons. Among other variables, baseline measures of fluid intelligence, WMP, trait affect, and school achievement were assessed during this phase. The testing took place as 
group testing in the class rooms. In addition to these measurements, children were also trained in operating the study smartphones for the AA phase. These touchscreen based smartphones (Dell Streak 5 with Android 2.2 operating system) were programmed with an application that was specifically developed for this study. All other functionalities of the smartphones (e.g., internet browser, cellular reception, microphone, application menu) were disabled; it was further ascertained that children could not exit or terminate the study application. Hence, the smartphones could only be used for the intended purposes of the present study. During the training session, the smartphones were distributed and detailed instructions were given by qualified research assistants. They instructed the children how to operate the smartphones and demonstrated each of the tasks and questions of the daily assessments. After that, smartphones were collected by the research assistants and redistributed at the beginning of the AA phase which started one week after the training session.

The AA phase lasted for 31 consecutive days and was conducted during the middle of the spring term (May / June 2012). During that time, four assessments per day were signaled by the smartphone, of which two took place during school hours (Occasion 1 at 8:50 am; Occasion 2 at 11:25 am). The third assessment started around 3:00 pm; the exact timing was individually adapted, depending on each child's schedule within a four hour window. The fourth session started around 7:00 pm (again +/- 2 hours to allow for individual schedules). This session is not relevant for the present study, since no WMP assessments were taken at the fourth occasion. Each assessment lasted approximately between 10 and 15 minutes. Assessments during school lessons (Occasions 1 and 2 during school days) were supervised by teachers and trained research assistants to ascertain that participating children were not distracted by their fellow students who did not participate (since not all students of a class participated in the study, non-participating students were provided with coloring books to work on during the assessments). Across all days and children, at least one valid data point on 
the five relevant study variables (see below) was present in 6,753 of the 10,137 occasions (109 children x 31 days x 3 measurement occasions per day), yielding an overall compliance rate of $66.6 \%$. Split up into the three occasions, compliance was slightly higher at Occasion 1 (68.9\%) and Occasion $2(69.4 \%)$ than at Occasion $3(61.6 \%)$. These compliance rates are slightly below the average, yet in the typical range of, compliance rates in comparable AA studies with children and adolescents reported in a recent review (Heron et al., 2017). ${ }^{2}$ The study protocol for the project FLUX (Assessment of Cognitive Performance FLUctuations in the School ConteXt) was approved by the ethics committee of the Faculty of Psychology and Sport Sciences at Goethe University in Frankfurt am Main, Germany (protocol number 2011$25 \mathrm{R} 2)$.

\section{Measurements}

\section{Momentary Measures (Ambulatory Assessment).}

Affect. Previous research in elementary school children has shown that the four scales PA, NA, activation, and deactivation, although correlated, are psychometrically distinct and should therefore be considered separately (Leonhardt et al., 2016). In the present study, each scale was assessed with three items each. Specifically, at each measurement occasion children were asked to indicate to what extent they felt each state right now ("Right now, I feel ...") on a five-point Likert scale ranging from 1 ("not at all") to 5 ("very much"). The items were good, fantastic, content (PA), unhappy, miserable, afraid (NA), active, interested, concentrated (activation), and exhausted, tired, faint (deactivation), respectively. The three items belonging to the same factor were averaged, resulting in four affect variables used for further analyses. A multilevel confirmatory factor analysis with four factors on the betweenperson level and four factors on the within-person level revealed adequate model fit in the

\footnotetext{
${ }^{2}$ We examined whether individual compliance rates were associated with mean levels in our study variables. Results showed that compliance rates were unrelated to gender, age, or any of the four affect scales, $|r|<.13, p\rangle$ .19 for all. There was a small but significant association with mean working memory performance, $r=.21, p=$ .03 , indicating that children with worse average performance tended to comply less with the measurement procedure.
} 
present sample, comparative fit index $(\mathrm{CFI})=.926$, root mean square error of approximation $(\mathrm{RMSEA})=.032$, standardized root mean square residual $(\mathrm{SRMR})=.043($ within $) / .073$ (between). Estimated reliabilities of the four scales were obtained as multilevel $\omega$ (Geldhof, Preacher, \& Zyphur, 2014). The respective estimates suggested good internal consistency on the between-person level, $\omega=.85$ (PA), $\omega=.99$ (NA), $\omega=.90$ (activation), and $\omega=.97$ (deactivation), respectively, and adequate internal consistency on the within-person level, $\omega=$ .70 (PA), $\omega=.75$ (NA), $\omega=.65$ (activation), and $\omega=.70$ (deactivation), respectively.

Working memory performance. At each measurement occasion, children worked on two memory updating tasks of working memory. In the numerical updating task, children were presented two (Load 2 task) or three (Load 3 task) digits (0-9) on the screen of the smartphone. After that, three (Load 2 task) or four (Load 3 task) updating operations were presented in the same place where the digits had appeared. These operations were subtractions and additions ranging from -2 to +2 . Children had to apply these operations to the digits that were presented in the corresponding location. After all operations had been presented, the two (Load 2 task) or three (Load 3 task) end results had to be entered within 20000ms. During each measurement occasion (i.e., three times per day) four Load 2 tasks and four Load 3 tasks were administered. Each of the total 20 responses $(4 \times 2$ results in the Load 2 tasks and $4 \times 3$ results in the Load 3 tasks) was coded as 1 if the correct response was given within the $20000 \mathrm{~ms}$ response window (0 otherwise). Mean accuracy of the $8(\operatorname{Load} 2)$ and $12(\operatorname{Load} 3)$ responses per measurement occasion was computed.

In the spatial memory updating task, children were presented a $4 \times 4$ grid on the smartphone screen. Two (Load 2 task) or three (Load 3 task) cartoon creatures were simultaneously presented, each in one of the 16 squares. Three (Load 2 task) or four (Load 3 task) updating operations were sequentially presented. These operations were represented as colored arrows positioned at the center of the grid. These arrows indicated movements of the 
cartoon creature with the corresponding color (e.g., if a red arrow facing downward appeared this indicated that the red creature had moved one square downward). After all updating operations had been shown, children had to indicate the position of the two or three creatures by tapping the respective square within $30000 \mathrm{~ms}$. Four blocks of the Load 2 task and four blocks of the Load 3 task were presented and the average accuracy across the $8(\operatorname{Load} 2)$ and 12 (Load 3) responses per measurement occasion was computed.

Previous research using the same $\operatorname{data}^{3}$ as the present study (Dirk \& Schmiedek, 2016) showed that the four performance indicators (numerical Load 2, numerical Load 3, spatial Load 2, and spatial Load 3) load on one common factor on both the between-person and the within-person level. We therefore aggregated the four indicators into one accuracy score per measurement occasion. For detailed information on the tasks and psychometric properties of this assessment see Dirk and Schmiedek (2016) and Galeano Weber, Dirk, and Schmiedek (2018).

\section{Data Analysis}

In a first step, four multilevel models were run in which WMP was predicted by one affect scale (PA, activation, NA, deactivation) each. To control for retest effects, a linear effect of measurement occasion was added in the model. Random effects were estimated for the intercept, the focal predictor (affect) and time. That is, child i's WMP at measurement occasion $t\left(\mathrm{WMP}_{t i}\right)$ was predicted by this child's affect at the same measurement occasion $\left(\right.$ aff $\left._{t i}\right)$ and time $\left(\right.$ time $\left._{t i}\right)$ :

Level 1:

$$
W M P_{t i}=\beta_{0 i}+\beta_{1 i} \cdot \text { time }_{t i}+\beta_{2 i} \cdot \operatorname{aff}_{t i}+\varepsilon_{t i}
$$

Level 2:

$$
\beta_{0 i}=\gamma_{00}+v_{0 i}
$$

\footnotetext{
${ }^{3}$ We note that we excluded one child from the present analyses that had been included in the previous publication.
} 


$$
\begin{aligned}
& \beta_{1 i}=\gamma_{10}+\mathrm{v}_{1 i} \\
& \beta_{2 i}=\gamma_{20}+\mathrm{v}_{2 i}
\end{aligned}
$$

Affect was centered on the respective person mean to obtain an unbiased estimate of the intra-individual effect (Wang \& Maxwell, 2015); time was centered on the $50^{\text {th }}$ measurement occasion and raw scores were divided by ten. Correlations between random effects were estimated. In a next step, intra-individual couplings were extracted as estimates (specifically, best linear unbiased predictors, or BLUPS) of person specific regression coefficients $\left(\beta_{2 i}\right)$. Couplings between NA and WMP and between deactivation and WMP, respectively, were multiplied by -1 in order to facilitate interpretation: Positive coupling estimates represent an association between affect and WMP in the expected direction (i.e., positive association of WMP with PA and activation, negative association with NA and deactivation). Person means of the five variables of interest (four affect scales and WMP) were computed as each child's arithmetic mean across all observations. These mean scores and the four coupling estimates were then subjected to a mixture model analysis (MMA). Since the variances of these nine variables were substantially heterogeneous and unequal variances affect the solution of the MMA (Steinley \& Brusco, 2011), we transformed them prior to the analyses. Specifically, we standardized the variables via a variance-to-range weighting procedure which has been shown to be superior to traditional transformations such as the z-standardization (Steinley \& Brusco, 2008). Within-class variances of the nine indicators were constrained to equality across classes. Correlations between the couplings of WMP with PA and activation, the couplings of WMP with NA and deactivation, mean PA and activation, and mean NA and deactivation, respectively, were estimated within each class. This MMA allows for examining whether the multivariate distribution of the study variables might represent a mixture of different distributions arising from distinct subgroups in the population. That is, in these models we examined whether the total sample might consist of 
various subsamples (classes) that differ in their distributions of the nine study variables (five person means and four couplings). Utilizing concepts derived from the theoretical account of ES, it can be expected that four classes can be identified that differ in the extent to which their members' affect is coupled with WMP.

The MMA was conducted in Mplus version 8 (Muthén \& Muthén, 2017), all other analyses using R version 3.4.0 for Windows (R core team, 2017). Multilevel models were estimated using the lme4 package (Bates, Mächler, Bolker, \& Walker, 2015); 95\% bootstrap confidence intervals for multilevel model parameters were obtained via the confint.merMod function of the lme4 package. A conventional $\alpha$-level of .05 was set for all analyses.

\section{Results}

Table 1 depicts descriptive statistics on the person level. PA correlated positively with activation, $r=.79, p<.001$, and negatively with NA, $r=-.30, p=.002$, and deactivation, $r=-$ $.23, p=.016$, respectively. Activation was not significantly related to both NA, $r=-.17, p=$ .077 , and deactivation, $r=-.18, p=.061$. Deactivation and NA were strongly positively correlated on the person level, $r=.90, p<001$. Average WMP was negatively associated with average NA, $r=-.33, p<.001$, and deactivation, $r=-.29, p=.002$, and positively associated with average $\mathrm{PA}, r=.27, p=.005$.

\section{Multilevel Models}

We estimated separate models for each of the four predictors of interest. Table 2 depicts the results. Fixed effects were statistically significant for NA and deactivation, but not PA and activation. Importantly, random effects for the focal predictors were statistically significant for all predictors. That is, although the effect of PA (activation) on WMP was not statistically significant for the average sample, there were statistically meaningful interindividual differences in the strength of the intra-individual association of PA (activation) and WMP. This was evident by both significant likelihood ratio tests (comparing models with vs. 
without random effects for the predictors), $\chi^{2}(3)>22.77, p<.001$ for all, and lower bounds of the confidence intervals for the random effect standard deviations markedly above 0 (see Table 2). ${ }^{4}$

\section{Structure of Within-Person Couplings}

From the multilevel models shown in Table 2, we extracted each child's estimated couplings (see Data Analysis for details). Table 3 shows the correlations of these personspecific within-person couplings. All correlations were positive and (with the exception of the coupling of activation and deactivation) statistically significant. Correlations for the couplings of PA and activation, $r=.67$, and NA and deactivation, $r=.69$, were substantial. The upper bounds of the $95 \%$ bootstrap confidence intervals for these two correlations were, however, markedly smaller than 1 , suggesting that these couplings are distinct from one another.

We then subjected these four variables, as well as the person means of the four predictors (PA, activation, NA, deactivation) and the person mean of WMP across all observations to a MMA. Models with two to six latent classes were estimated; only models with two, three, and four classes successfully converged and only these were examined in detail. Model comparisons are depicted in Table 4. Based on these results, a four-class model provided the best description of the data. The four classes were made up of 16, 51, 19, and 23 children, respectively. Average latent class probabilities for the four classes were $.97, .95, .97$, and .99 , respectively, suggesting good classification of individuals into the four latent classes.

Figure 1 depicts the means of the nine variables (i.e., the four couplings and the person means of WMP and the four affect scales) separately for the four latent classes (note that for better interpretability, Figure 1 depicts z-standardized values). The largest class (Class 2) was

\footnotetext{
${ }^{4}$ In post-hoc analyses, we investigated whether including a quadratic time trend (as fixed and random effect) would alter the conclusions. Results revealed a significant positive quadratic trend in all four models (indicating that the change in working memory performance was decelerated towards the end of the study period), $b>$ $0.001, p<.025$ for all. When including the quadratic time trend, the fixed effect for PA was significant, $b=$ $0.009, p=.036$. All other results remained unaltered (this also applies to the results reported later in the manuscript).
} 
characterized by above-average WMP and PA, as well as below-average NA and deactivation. Couplings in this group were all around or slightly below the sample average. We interpreted this class as representing the group of children with low sensitivity. Class 1 was characterized by below-average WMP, NA, and deactivation, as well as above-average mean PA and activation. Children in this class exhibited above-average couplings of WMP with PA, activation, and NA, as well as deactivation (descriptively). The above average couplings for all four predictors in this class are consistent with the notion of a general sensitivity group. Children in Class 3 were characterized by below-average WMP, mean NA, and mean activation, but above-average activation-WMP couplings; this pattern is broadly in line with a group of children high in vantage sensitivity. Finally, Class 4 also had belowaverage mean levels in WMP and, additionally, below-average mean PA. Mean NA and deactivation were markedly above the sample average. WMP couplings with PA and activation were around average for children in this class, but couplings with NA and deactivation were about $.75 S D$ s above the sample average, as would be expected for a vulnerability group.

Figure 2 depicts each child's intra-individual couplings (separately for the four predictors; please note again that couplings with NA and deactivation were multiplied by -1 ). Children with couplings one or more standard errors away from zero are marked in black. The mean couplings together with their associated 95\% confidence interval are reported in Table 5. Figure 2 and Table 5 show that (a) couplings in Class 2 (low sensitivity group) were close to zero, (b) children in Class 3 (vantage sensitivity group) showed overall a positive association of activation (and to a lesser extent a negative association of NA) with WMP, (c) in Class 4 (vulnerability group), the associations of NA and deactivation, respectively, with WMP were negative, while no overall association between PA/activation and WMP could be observed, and (d) Class 1 (general sensitivity) showed negative effects of NA and 
deactivation, respectively, on WMP, and positive effects of PA and activation, respectively, on WMP.

\section{Discussion}

WMP reliably fluctuates within children (Dirk \& Schmiedek, 2016), yet little is known about the predictors of these fluctuations. Why do children sometimes perform better or worse on the same tasks? In the present study, we focused on one group of predictors: affective experiences in everyday lives in a sample of elementary school children. Building on previous research, we expected that momentary states characterized by positive affective experiences (positive valence, high energetic arousal) would be associated with better WMP, while negative affective experiences (negative valence, low energetic arousal) would be associated with worse WMP. Regarding the average associations with indicators of negative affectivity (NA, deactivation), our findings are consistent with the greatest portion of prior research that has reported a negative effect of NA on cognitive performance (Brose et al., 2014; Fartoukh et al., 2014; Patel et al., 2016; Pnevmatikos \& Trikkaliotis, 2013): At occasions when children reported higher NA or higher deactivation, their WMP was worse compared to occasions with lower NA / deactivation. This finding is consistent with theoretical accounts such as the resource allocation model (Ellis \& Ashbrook, 1988) which proposes that the regulation of negative affective states takes up resources that cannot be simultaneously engaged for cognitive tasks requiring working memory resources. We note that, although the average effects across the whole sample were statistically significant, there were meaningful interindividual differences in the intra-individual association between NA / deactivation and WMP, indicating that children differed in the magnitude of this association. Further investigating these heterogeneities via mixture models showed that there were two groups of children (latent Classes 1 and 4) who exhibited particularly strong NA-/deactivation-WMP couplings. 
Positive affective states (PA / activation) were, on average, not significantly coupled with WMP. However, our results showed that there were substantial inter-individual differences in the intra-individual association of PA / activation with WMP. Mixture model analyses suggested that in two groups of children (latent Classes 1 and 3), the (positive) association of activation with WMP was statistically significant: That is, these children showed better performance on the working memory tasks at occasions when they reported higher perceived energetic arousal. Children in latent Class 1 further also exhibited pronounced (positive) intra-individual PA-WMP couplings.

Taken together, our findings emphasize the importance of considering inter-individual differences when investigating intra-individual affect-WMP couplings: Had we only considered the average (fixed) effects, we would have concluded that there was a negative association of NA/deactivation with WMP, and no association between PA/activation and WMP. The picture seems to be a bit more nuanced, however: While the negative association between NA and WMP primarily differed in magnitude between children (larger in Classes 1 and 4), differences in the PA/activation/deactivation associations with WMP were more complex: For some children (latent Class 2), all these within-person associations were close to zero. Other children (Classes 1 and 4) showed pronounced couplings between deactivation and WMP. We note that these were the same children who exhibited particularly strong NAWMP couplings as well. In order to better understand the structure of these inter-individual differences, we interpret these groups along the terminology proposed in the ES framework.

\section{Inter-Individual Differences in Affect-WMP Couplings}

Individuals differ in the degree to which they are affected by their environment. While the processes accounting for these differences are largely unknown (see below for a brief discussion), the assumption of the existence of such differences is shared among various theoretical frameworks (Aron, Aron, \& Jagiellowicz, 2012; Belsky \& Pluess, 2009; Boyce 
\& Ellis, 2005; Del Giudice et al., 2011; Pluess \& Belsky, 2013). According to the ES account (Pluess, 2015), individuals differ in the effect of the environment on physiological, psychological, and behavioral outcomes, and these differences can be structured in four groups: low sensitivity, vulnerability, vantage sensitivity, and general sensitivity. These four groups resemble the four latent classes identified in the present work: Class 1 consisted of children with particularly strong couplings for all four affect variables with WMP, and therefore paralleled the idea of a general sensitivity group. These children showed a strong (positive) effect of PA and activation on WMP, but also a strong (negative) effect of NA and deactivation on WMP. Hence, cognitive performance of these children is associated with current affective states in a "for-better-and-for-worse" manner (Belsky \& Pluess, 2009). Children's WMP in Class 2 was substantially less affected by their current affective state. More specifically, couplings in this group were smaller than in Class 1 (NA) or close to zero (PA, activation, deactivation) in line with the idea of a low sensitivity group. Notably, since genetic predispositions towards heightened ES, such as the dopamine D4 receptor (DRD4) gene 7-repeat allele (Bakermans-Kranenburg, van IJzendoorn, Pijlman, Mesman, \& Juffer, 2008) or the serotonin transporter-linked polymorphic region (5-HTTLPR) short allele (van Ijzendoorn, Belsky, \& Bakermans-Kranenburg, 2012), are expected to be prevalent in a minority of the population only (Wolf, van Doorn, \& Weissing, 2008), it can be expected that the largest proportion of children should not demonstrate pronounced responsiveness. This is in line with our results which revealed that approximately half (47\%) of the children in our sample were categorized into the low sensitivity group (Class 2).

Latent Classes 3 and 4 further emphasize that inter-individual differences in responsivity to positive and negative experiential influences, respectively, might not necessarily be consequences of the same mechanism. Specifically, children in Class 3 on average exhibited positive couplings between activation and WMP, coinciding with the 
proposal of a vantage sensitivity group. Class 4 , on the other hand, was characterized by particularly strong (negative) couplings of WMP with NA and deactivation, paralleling the pattern of a vulnerability group. These results, when interpreted in the ES framework, can provide important information with regard to potential mechanisms accounting for interindividual differences in the effects of environmental influences.

\section{Potential Mechanisms Accounting for Inter-Individual Differences in Reactivity}

Previous theorizing on potential mechanisms accounting for inter-individual differences in the effect of environmental inputs has often not differentiated between the impacts of positive vs. negative environments. For example, the BSC (Boyce \& Ellis, 2005) and its later refinement as the ACM (Del Giudice et al., 2011) propose that differences in the sensitivity to environmental influences are a consequence of differences in physiological stress reactivity. According to this view, individuals differ in the sensitivity of various subsystems of the stress response system (SRS; i.e., the sympathetic and parasympathetic systems and the HPA axis) and these differences account for differences in the effects of environmental inputs on behavioral outcomes. Evidence for this proposition comes from research examining inter-individual differences in physiological stress reactivity. For example, in a study by El-Sheikh, Keller, and Erath (2007) inter-individual differences in skin conductance reactivity (a marker for reactivity of the sympathetic nervous system) moderated the longitudinal association between parental marital conflict and internalizing problems among girls (but not boys). This finding is in line with the assumption that differences in SRS drive differences in environmental effects. So far, however, whether differences in physiological stress reactivity can account for an “organism's adjustment to both positive and negative events", as postulated by Del Giudice et al. (2011; p. 1572) remains an open question. Our findings suggested a separation between vantage sensitive children and vulnerable children, hence challenging the assumption that a single mechanism underlies 
environmental sensitivity to both positive and negative input. Nevertheless, it could be that differences in the responsivity of various subsystems of the SRS interact in giving rise to the observed structure of inter-individual differences in the intra-individual couplings of affective states and WMP. Based on our findings, a more fine-grained analysis of interactive effects of these subsystems, as well as their interaction with serotonergic and dopaminergic pathways seems to be a promising avenue for future research.

Another mechanism that has been discussed to underlie differences in ES is sensory processing sensitivity (SPS) - the tendency to be "more or less responsive, reactive, flexible, or sensitive to the environment" (Aron et al., 2012). Recent advances in the measurement of inter-individual differences in SPS in adults (Lionetti et al., 2018) and children (Pluess et al., 2018) have shown that this construct can be further divided into three subscales, of which one (aesthetic sensitivity) has been related to positive emotionality and vantage sensitivity, and two (ease of excitation; low sensory threshold) have been more closely related to negative emotionality and vulnerability (Pluess et al., 2018). These findings are concordant with the observation of the present study that differences in sensitivity to positive contexts and sensitivity to negative contexts seem to be not necessarily two sides of the same coin. An interesting agenda for future research would be to examine differences in SPS between the latent classes identified by intra-individual couplings in the present study: Building on prior psychometric work, suggesting some discriminant validity among the three SPS subscales (Lionetti et al., 2018; Pluess et al., 2018) it might be expected that children in the vulnerability group (latent Class 4 in the present research) show elevated levels in SPS, ease of excitation, and low sensory threshold, whereas children from the vantage sensitivity group (latent Class 3 in the present research) show higher levels in SPS and aesthetic sensitivity than less responsive children. Children in the general sensitivity group (Class 1) might exhibit higher levels in SPS and all three subscales (aesthetic sensitivity, ease of excitation, and low 
sensory threshold). Ultimately, investigating the mechanisms underlying inter-individual differences in ES is beyond the scope of the present work, but our results point towards potentially interesting directions for future research, emphasizing the importance of accounting for mechanisms that can explain evidence of both convergence (general sensitivity group) and divergence (vulnerability group; vantage sensitivity group) between responsivity to positive and negative states, respectively.

\section{Limitations}

In interpreting the results, a number of limitations have to be considered. First, although fairly large for an AA study in the school context, the number of participants in the study has to be considered rather small for a mixture model analysis. The sample size might have been too small to reveal a further differentiation into more latent classes. Specifically, models with more than four latent classes failed to converge, and we therefore cannot conclude that the reported four latent classes might not be divided further into smaller groups. Second, the tense arousal dimension of affective experiences that has been shown to be relevant in elementary school children's everyday affective experiences (Leonhardt et al., 2016) was not assessed in the present research. Negative tense arousal (such as stress) has been related to intra-individual fluctuations in cognitive performance (Sliwinski et al., 2006) and future research needs to determine if vulnerability to stress co-varies with vulnerabilities to the other two negative affectivity dimensions assessed in the present study (NA, deactivation). Third, relevant covariates and predictors of membership in the latent classes remain unknown. As discussed above, physiological stress reactivity and sensory processing sensitivity would be prime candidates for this purpose and should be explored in future research. Fourth, our research primarily targeted inter-individual differences in the intraindividual coupling of affective states and WMP and we utilized the ES framework to better understand the structure of these inter-individual differences. In order to interpret our findings 
in light of the ES framework, we need to make one of the following two assumptions: Either (a) children's momentary affective experiences are interpreted as proxy measures for positive and negative environmental input, or (b) both affective states and WMP are considered as outcomes of the common cause environmental input. With regard to the first possibility, affective states are most likely only distal indicators for environmental inputs that are central to ES. In fact, children might already differ in the extent to which they respond to positive / negative environmental input (e.g., the occurrence of stressors or uplifting events) in terms of PA and NA. However, as long as assumption (b) holds true, meaning that inter-individual differences in PA / NA reactivity (i.e., difference in the degree to which PA / NA are affected by positive / negative environmental input) are predicted by the same characteristics as are inter-individual differences in WMP reactivity (i.e., difference in the degree to which WMP is affected by positive / negative environmental input), this does not pose a threat to the conclusions drawn in the present research. We note, however, that this assumption needs to be examined in future research (Pluess, 2018). No concurrent assessments of such events and WMP were available in the present study, precluding us from directly assessing the effect of events on WMP. Future research should consider implementing both stressor events and uplifting events together with concurrent WMP assessments to more directly assess the impact of environmental input on cognitive performance and inter-individual differences therein.

\section{Conclusions}

Intra-individual fluctuations in elementary school children's WMP were associated with concurrently measured fluctuations in affective states. Across the whole sample, higher negative affect and higher deactivation were associated with poorer performance, while no overall associations of WMP with positive affect and activation could be detected. Children differed in the degree to which their performance was associated with their affective states: In 
approximately half of the sample, WMP was more or less unrelated to current affect. One group of children showed pronounced decrements in performance when negative affect or deactivation were higher than usual, while another group exhibited elevated performance in situations of high energetic arousal (activation). One further group showed positive associations with positive affective experiences and negative associations with negative affective experiences. Differences between the four groups might be a result of genetic by early environment interactions that are mediated by differences in ES. 


\section{References}

Aron, E. N., Aron, A., \& Jagiellowicz, J. (2012). Sensory processing sensitivity: A review in the light of the evolution of biological responsivity. Personality and Social Psychology Review, 16, 262-282. https://doi.org/10.1177/1088868311434213

Ashby, F. G., Isen, A. M., \& Turken, A. U. (1999). A neuropsychological theory of positive affect and its influence on cognition. Psychological Review, 106, 529-550. https://doi.org/10.1037//0033-295X.106.3.529

Ashcraft, M. H., \& Kirk, E. P. (2001). The relationships among working memory, math anxiety, and performance. Journal of Experimental Psychology: General, 130, 224-237. https://doi.org/10.1037//0096-3445.130.2.224

Bakermans-Kranenburg, M. J., van IJzendoorn, M. H., Pijlman, F. T. A., Mesman, J., \& Juffer, F. (2008). Experimental evidence for differential susceptibility: Dopamine D4 receptor polymorphism (DRD4 VNTR) moderates intervention effects on toddlers' externalizing behavior in a randomized controlled trial. Developmental Psychology, 44, 293-300. https://doi.org/10.1037/0012-1649.44.1.293

Bates, D., Mächler, M., Bolker, B., \& Walker, S. (2015). Fitting lnear mixed-effects models using lme4. Journal of Statistical Software, 67. https://doi.org/10.18637/jss.v067.i01

Belsky, J., \& Pluess, M. (2009). Beyond diathesis stress: Differential susceptibility to environmental influences. Psychological Bulletin, 135, 885-908. https://doi.org/10.1037/a0017376

Boyce, W. T., \& Ellis, B. J. (2005). Biological sensitivity to context: I. An evolutionarydevelopmental theory of the origins and functions of stress reactivity. Development and Psychopathology, 17, 271-301.

Brose, A., Lövdén, M., \& Schmiedek, F. (2014). Daily fluctuations in positive affect positively co-vary with working memory performance. Emotion, 14, 1-6. https://doi.org/10.1037/a0035210 
Brose, A., Schmiedek, F., Lövdén, M., \& Lindenberger, U. (2012). Daily variability in working memory is coupled with negative affect: The role of attention and motivation. Emotion, 12, 605-617. https://doi.org/10.1037/a0024436

Del Giudice, M., Ellis, B. J., \& Shirtcliff, E. A. (2011). The Adaptive Calibration Model of stress responsivity. Neuroscience and Biobehavioral Reviews, 35, 1562-1592. https://doi.org/10.1016/j.neubiorev.2010.11.007

Diamond, A. (2013). Executive functions. Annual Review of Psychology, 64, 135-168. https://doi.org/10.1146/annurev-psych-113011-143750

Dirk, J., \& Schmiedek, F. (2016). Fluctuations in elementary school children's working memory performance in the school context. Journal of Educational Psychology, 108, 722739. https://doi.org/10.1037/edu0000076

Dirk, J., \& Schmiedek, F. (2017). Variability in children's working memory is coupled with perceived disturbance: An ambulatory assessment study in the school and out-of-school context. Research in Human Development, 14, 200-218.

https://doi.org/10.1080/15427609.2017.1340051

Ellis, B. J., Boyce, W. T., Belsky, J., Bakermans-Kranenburg, M. J., \& van IJzendoorn, M. H. (2011). Differential susceptibility to the environment: An evolutionary-neurodevelopmental theory. Development and Psychopathology, 23, 7-28. https://doi.org/10.1017/S0954579410000611

Ellis, H. C., \& Ashbrook, P. W. (1988). Resource allocation model of the effects of depressed mood states on memory. In K. Fiedler \& J. Forgas (Eds.), Affect, cognition and social behavior: New evidence and integrative attempts (pp. 25-43). Toronto: Hogrefe.

Ellis, H. C., Moore, B. A., Varner, L. J., A. Ottaway, S., \& S. Becker, A. (1997). Depressed mood, task organization, cognitive interference, and memory: Irrelevant thoughts predict recall performance. Journal of Social Behavior and Personality, 12. 
El-Sheikh, M., Keller, P. S., \& Erath, S. A. (2007). Marital conflict and risk for child maladjustment over time: Skin conductance level reactivity as a vulnerability factor. Journal of Abnormal Child Psychology, 35, 715-727. https://doi.org/10.1007/s10802-007$9127-2$

Fartoukh, M., Chanquoy, L., \& Piolat, A. (2014). Mood induction in children: Effect of the affective valence of a text on phonological working memory. Advances in Cognitive Psychology, 10, 113-118. https://doi.org/10.5709/acp-0162-z

Galeano Weber, E., Dirk, J., \& Schmiedek, F. (2018). Variability in the precision of children's spatial working memory. Journal of Intelligence, 6,8 . https://doi.org/10.3390/jintelligence6010008

Gathercole, S. E., Pickering, S. J., Knight, C., \& Stegmann, Z. (2004). Working memory skills and educational attainment: Evidence from national curriculum assessments at 7 and 14 years of age. Applied Cognitive Psychology, 18, 1-16. https://doi.org/10.1002/acp.934

Geldhof, G. J., Preacher, K. J., \& Zyphur, M. J. (2014). Reliability estimation in a multilevel confirmatory factor analysis framework. Psychological Methods, 19, 72-91. https://doi.org/10.1037/a0032138

Hamaker, E. L. (2012). Why researchers should think "within-person". A paradigmatic rationale. In M. R. Mehl \& T. S. Conner (Eds.), Handbook of research methods for studying daily life (pp. 43-61). New York: Guilford Press.

Heron, K. E., Everhart, R. S., McHale, S. M., \& Smyth, J. M. (2017). Using mobiletechnology-based ecological momentary assessment (EMA) methods with youth: A systematic review and recommendations. Journal of Pediatric Psychology, 42, 1087-1107. https://doi.org/10.1093/jpepsy/jsx078

Ilkowska, M., \& Engle, R. W. (2010). Working memory capaciry and self-regulation. In R. H. Hoyle (Ed.), Handbook of personality and self-regulation (365-290). Chichester: Wiley Blackwell. 
Könen, T., Dirk, J., \& Schmiedek, F. (2015). Cognitive benefits of last night's sleep: Daily variations in children's sleep behavior are related to working memory fluctuations. Journal of Child Psychology and Psychiatry, and Allied Disciplines, 56, 171-182. https://doi.org/10.1111/jcpp.12296

Leonhardt, A., Könen, T., Dirk, J., \& Schmiedek, F. (2016). How differentiated do children experience affect? An investigation of the within- and between-person structure of children's affect. Psychological Assessment, 28, 575-585. https://doi.org/10.1037/pas0000195

Lionetti, F., Aron, A., Aron, E. N., Burns, G. L., Jagiellowicz, J., \& Pluess, M. (2018). Dandelions, tulips and orchids: Evidence for the existence of low-sensitive, mediumsensitive and high-sensitive individuals. Translational Psychiatry, 8, 24. https://doi.org/10.1038/s41398-017-0090-6

Lupien, S. J., Gillin, C. J., \& Hauger, R. L. (1999). Working memory is more sensitive than declarative memory to the acute effects of corticosteroids: A dose-response study in humans. Behavioral Neuroscience, 113, 420-430. https://doi.org/10.1037/07357044.113.3.420

Martin, E. A., \& Kerns, J. G. (2011). The influence of positive mood on different aspects of cognitive control. Cognition \& Emotion, 25, 265-279. https://doi.org/10.1080/02699931.2010.491652

Mitchell, R. L. C., \& Phillips, L. H. (2007). The psychological, neurochemical and functional neuroanatomical mediators of the effects of positive and negative mood on executive functions. Neuropsychologia, 45, 617-629. https://doi.org/10.1016/j.neuropsychologia.2006.06.030

Miyake, A., Friedman, N. P., Emerson, M. J., Witzki, A. H., Howerter, A., \& Wager, T. D. (2000). The unity and diversity of executive functions and their contributions to complex 
"Frontal Lobe" tasks: A latent variable analysis. Cognitive Psychology, 41, 49-100. https://doi.org/10.1006/cogp.1999.0734

Moffitt, T. E., Arseneault, L., Belsky, D., Dickson, N., Hancox, R. J., Harrington, H., . . . Caspi, A. (2011). A gradient of childhood self-control predicts health, wealth, and public safety. Proceedings of the National Academy of Sciences of the United States of America, 108, 2693-2698. https://doi.org/10.1073/pnas.1010076108

Molenaar, P. C. M. (2004). A manifesto on psychology as idiographic science: Bringing the person back into scientific psychology, this time forever. Measurement: Interdisciplinary Research \& Perspective, 2, 201-218. https://doi.org/10.1207/s15366359mea0204_1

Muthén, L. K., \& Muthén, B. O. (2017). Mplus User's Guide. Eighth Edition. Los Angeles, CA: Muthén \& Muthén.

Palmiero, M., Nori, R., Rogolino, C., D'Amico, S., \& Piccardi, L. (2015). Situated navigational working memory: The role of positive mood. Cognitive Processing, 16 Suppl 1,327-330. https://doi.org/10.1007/s10339-015-0670-4

Patel, N., Vytal, K., Pavletic, N., Stoodley, C., Pine, D. S., Grillon, C., \& Ernst, M. (2016). Interaction of threat and verbal working memory in adolescents. Psychophysiology, 53, 518-526. https://doi.org/10.1111/psyp.12582

Pluess, M. (2015). Individual differences in environmental sensitivity. Child Development Perspectives, 9, 138-143. https://doi.org/10.1111/cdep.12120

Pluess, M., Assary, E., Lionetti, F., Lester, K. J., Krapohl, E., Aron, E. N., \& Aron, A. (2018). Environmental sensitivity in children: Development of the Highly Sensitive Child Scale and identification of sensitivity groups. Developmental Psychology, 54, 51-70. https://doi.org/10.1037/dev0000406

Pluess, M., \& Belsky, J. (2013). Vantage sensitivity: Individual differences in response to positive experiences. Psychological Bulletin, 139, 901-916.

https://doi.org/10.1037/a0030196 
Pnevmatikos, D., \& Trikkaliotis, I. (2013). Intraindividual differences in executive functions during childhood: The role of emotions. Journal of Experimental Child Psychology, 115, 245-261. https://doi.org/10.1016/j.jecp.2013.01.010

R core team. (2017). R: A language and environment for statistical computing. R Foundation for Statistical Computing. Vienna, Austria. Retrieved from https:/www.R-project.org/

Riediger, M., Wrzus, C., Schmiedek, F., Wagner, G. G., \& Lindenberger, U. (2011). Is seeking bad mood cognitively demanding? Contra-hedonic orientation and workingmemory capacity in everyday life. Emotion, 11, 656-665. https://doi.org/10.1037/a0022756

Russell, J. A., \& Barrett, L. F. (1999). Core affect, prototypical emotional episodes, and other things called emotion: Dissecting the elephant. Journal of Personality and Social Psychology, 76, 805-819. https://doi.org/10.1037/0022-3514.76.5.805

Sliwinski, M. J., Smyth, J. M., Hofer, S. M., \& Stawski, R. S. (2006). Intraindividual coupling of daily stress and cognition. Psychology and Aging, 21, 545-557. https://doi.org/10.1037/0882-7974.21.3.545

Steinley, D., \& Brusco, M. J. (2008). A new variable weighting and selection procedure for K-means cluster analysis. Multivariate Behavioral Research, 43, 77-108. https://doi.org/10.1080/00273170701836695

Steinley, D., \& Brusco, M. J. (2011). Evaluating mixture modeling for clustering: Recommendations and cautions. Psychological Methods, 16, 63-79. https://doi.org/10.1037/a0022673

Steyer, R., Schwenkmezger, P., Notz, P., \& Eid, M. (1994). Testtheoretische Analysen des Mehrdimensionalen Befindlichkeitsfragebogen (MDBF) [Theoretical analysis of a multidimensional mood questionnaire (MDBF)]. Diagnostica, 40, 320-328.

Stumm, S. von. (2016). Is day-to-day variability in cognitive function coupled with day-today variability in affect? Intelligence, 55, 1-6. https://doi.org/10.1016/j.intell.2015.12.006 
Trull, T. J., \& Ebner-Priemer, U. (2013). Ambulatory assessment. Annual Review of Clinical Psychology, 9, 151-176. https://doi.org/10.1146/annurev-clinpsy-050212-185510

Van Ijzendoorn, M. H., Belsky, J., \& Bakermans-Kranenburg, M. J. (2012). Serotonin transporter genotype 5HTTLPR as a marker of differential susceptibility? A meta-analysis of child and adolescent gene-by-environment studies. Translational Psychiatry, 2, e147. https://doi.org/10.1038/tp.2012.73

Wang, L., \& Maxwell, S. E. (2015). On disaggregating between-person and within-person effects with longitudinal data using multilevel models. Psychological Methods, 20, 63-83. https://doi.org/10.1037/met0000030

Watson, D., \& Tellegen, A. (1985). Toward a consensual structure of mood. Psychological Bulletin, 98, 219-235. https://doi.org/10.1037/0033-2909.98.2.219

Wolf, M., van Doorn, G. S., \& Weissing, F. J. (2008). Evolutionary emergence of responsive and unresponsive personalities. Proceedings of the National Academy of Sciences of the United States of America, 105, 15825-15830. https://doi.org/10.1073/pnas.0805473105

Yang, H., Yang, S., \& Isen, A. M. (2013). Positive affect improves working memory: Implications for controlled cognitive processing. Cognition \& Emotion, 27, 474-482. https://doi.org/10.1080/02699931.2012.713325

Zuckerman, M. (1999). Vulnerability to psychopathology: A biosocial model (1. ed.). Washington, DC: American Psychological Ass. 
Table 1

Descriptive Statistics

\begin{tabular}{|c|c|c|c|c|c|c|c|c|c|c|}
\hline & & $\begin{array}{c}\text { Mean } \\
(S D)\end{array}$ & $\mathrm{ICC}$ & Range & 2 & 3 & 4 & 5 & 6 & 7 \\
\hline 1 & Age & $\begin{array}{c}9.88 \\
(0.61)\end{array}$ & - & $8.1-11.2$ & -.18 & .02 & .00 & -.04 & .00 & $.23 *$ \\
\hline 2 & Gender $^{\mathrm{a}}$ & $\begin{array}{l}0.42 \\
(.50)\end{array}$ & - & $0-1$ & & .04 & -.06 & -.02 & .03 & .08 \\
\hline 3 & Positive Affect & $\begin{array}{c}4.05 \\
(0.77)\end{array}$ & .435 & $1.76-5.00$ & & & $.79 *$ & $-.30 *$ & $-.23 *$ & $.27 *$ \\
\hline 4 & Activation & $\begin{array}{c}3.69 \\
(0.94)\end{array}$ & .538 & $1.21-5.00$ & & & & -.17 & -.18 & .09 \\
\hline 5 & Negative Affect & $\begin{array}{c}1.54 \\
(0.60)\end{array}$ & .367 & $1.00-3.53$ & & & & & $.90 *$ & $-.33 *$ \\
\hline 6 & Deactivation & $\begin{array}{c}1.70 \\
(0.63)\end{array}$ & .371 & $1.00-3.55$ & & & & & & $-.29 *$ \\
\hline 7 & Working memory & $\begin{array}{c}0.61 \\
(0.21)\end{array}$ & .522 & $0.13-0.97$ & & & & & & \\
\hline
\end{tabular}

Note. Table depicts descriptive statistics on the person-level. ICC = intra-class correlation.

${ }^{\mathrm{a}} 0=$ male; $1=$ female. ${ }^{*} p<.05 . N=107$ (age); $N=108$ (gender); $N=109$ (other variables). 
Table 2

Multilevel Models (Predicting Working Memory Performance)

\begin{tabular}{|c|c|c|c|c|}
\hline & Positive Affect & Activation & Negative Affect & Deactivation \\
\hline \multicolumn{5}{|l|}{ Fixed Effects } \\
\hline Intercept & $\begin{array}{c}0.636^{*} \\
{[0.596,0.674]}\end{array}$ & $\begin{array}{c}0.639^{*} \\
{[0.601,0.677]}\end{array}$ & $\begin{array}{c}0.638^{*} \\
{[0.599,0.675]}\end{array}$ & $\begin{array}{c}0.637^{*} \\
{[0.599,0.676]}\end{array}$ \\
\hline Time & $\begin{array}{c}-0.019^{*} \\
{[-0.023,-0.015]}\end{array}$ & $\begin{array}{c}-0.018^{*} \\
{[-0.022,-0.014]}\end{array}$ & $\begin{array}{c}-0.019^{*} \\
{[-0.023,-0.014]}\end{array}$ & $\begin{array}{c}-0.019^{*} \\
{[-0.023,-0.015]}\end{array}$ \\
\hline Predictor & $\begin{array}{c}0.008 \\
{[-0.001,0.018]}\end{array}$ & $\begin{array}{c}0.008 \\
{[-0.002,0.017]}\end{array}$ & $\begin{array}{c}-0.023^{*} \\
{[-0.034,-0.013]}\end{array}$ & $\begin{array}{c}-0.011^{*} \\
{[-0.020,-0.002]}\end{array}$ \\
\hline \multicolumn{5}{|l|}{$\begin{array}{l}\text { Random Effects } \\
\text { (Standard Deviations) }\end{array}$} \\
\hline Intercept & $\begin{array}{c}0.199 \\
{[0.172,0.227]}\end{array}$ & $\begin{array}{c}0.199 \\
{[0.171,0.226]}\end{array}$ & $\begin{array}{c}0.199 \\
{[0.171,0.226]}\end{array}$ & $\begin{array}{c}0.198 \\
{[0.171,0.226]}\end{array}$ \\
\hline Time & $\begin{array}{c}0.019 \\
{[0.016,0.022]}\end{array}$ & $\begin{array}{c}0.018 \\
{[0.015,0.021]}\end{array}$ & $\begin{array}{c}0.019 \\
{[0.016,0.022]}\end{array}$ & $\begin{array}{c}0.019 \\
{[0.016,0.023]}\end{array}$ \\
\hline Predictor & $\begin{array}{c}0.032 \\
{[0.023,0.041]}\end{array}$ & $\begin{array}{c}0.035 \\
{[0.025,0.044]}\end{array}$ & $\begin{array}{c}0.034 \\
{[0.024,0.044]}\end{array}$ & $\begin{array}{c}0.028 \\
{[0.017,0.036]}\end{array}$ \\
\hline $\begin{array}{l}\text { Level-1 Residual Standard } \\
\text { Deviation }\end{array}$ & $\begin{array}{c}0.170 \\
{[0.167,0.173]}\end{array}$ & $\begin{array}{c}0.169 \\
{[0.165,0.172]}\end{array}$ & $\begin{array}{c}0.169 \\
{[0.165,0.172]}\end{array}$ & $\begin{array}{c}0.170 \\
{[0.167,0.173]}\end{array}$ \\
\hline Pseudo- $R^{2}$ (Level 1) & $21.5 \%$ & $22.1 \%$ & $22.2 \%$ & $21.3 \%$ \\
\hline
\end{tabular}

Note. Table depicts point estimates ( $95 \%$ bootstrap confidence intervals in parentheses). Pseudo- $R^{2}$ was estimated as the proportion of residual (Level 1) variance explained by the model (compared to a baseline model which includes no predictors). ${ }^{*} p<.05$

$N=109$. 
Table 3

Intercorrelations of Intra-Individual Couplings

\begin{tabular}{llccc} 
& & 2 & 3 & 4 \\
\cline { 3 - 4 } 1 & Positive Affect & $.67^{*}$ & $.31^{*}$ & $.35^{*}$ \\
& & {$[.55, .76]$} & {$[.06, .52]$} & {$[.09, .57]$} \\
& & & $.25^{*}$ & .23 \\
3 & Netivation & & {$[.02, .45]$} & {$[-.01, .45]$} \\
& & & $.69^{*}$ \\
4 & Degative Affect & & {$[.52, .82]$} \\
\hline
\end{tabular}

Note. Couplings involving negative affect and deactivation have been multiplied by -1 to facilitate interpretation; high values on all estimates correspond to a strong coupling in the hypothesized direction. 95\% bootstrap confidence intervals are depicted in parentheses.

$* p<.05 . N=109$. 
Table 4

Model Comparisons

\begin{tabular}{lccccc}
\hline $\begin{array}{l}\text { Number of latent } \\
\text { classes }\end{array}$ & Log likelihood & $\begin{array}{c}\text { Number of free } \\
\text { parameters }\end{array}$ & $\begin{array}{c}\text { Scaling } \\
\text { correction } \\
\text { factor }\end{array}$ & BIC & Entropy \\
2 & -1699.233 & 36 & 1.367 & 3567.355 & 0.858 \\
3 & -1655.427 & 50 & 1.233 & 3545.422 & 0.887 \\
4 & -1619.981 & 64 & 1.144 & 3540.209 & 0.923 \\
\hline
\end{tabular}

Note. $\mathrm{BIC}=$ Bayesian information criterion. 
Table 5

Person-Specific Couplings Separated by Latent Class

\begin{tabular}{|c|c|c|c|c|}
\hline & $\begin{array}{c}\text { Class } 1(N=16) \\
\text { General Sensitivity }\end{array}$ & $\begin{array}{l}\text { Class } 2(N=51) \\
\text { Low Sensitivity }\end{array}$ & $\begin{array}{c}\text { Class } 3(N=19) \\
\text { Vantage Sensitivity }\end{array}$ & $\begin{array}{c}\text { Class } 4(N=23) \\
\text { Vulnerability }\end{array}$ \\
\hline Positive Affect & $\begin{array}{c}\mathbf{0 . 0 2 1 5} \\
{[0.0069,0.0362]}\end{array}$ & $\begin{array}{c}\mathbf{0 . 0 0 5 0} \\
{[0.0014,0.0086]}\end{array}$ & $\begin{array}{c}0.0075 \\
{[-0.0030,0.0179]}\end{array}$ & $\begin{array}{c}0.0070 \\
{[-0.0066,0.0205]}\end{array}$ \\
\hline Activation & $\begin{array}{c}\mathbf{0 . 0 2 6 8} \\
{[0.0133,0.0402]}\end{array}$ & $\begin{array}{c}-0.0022 \\
{[-0.0059,0.0015]}\end{array}$ & $\begin{array}{c}\mathbf{0 . 0 2 4 8} \\
{[0.0138,0.0357]}\end{array}$ & $\begin{array}{c}0.0035 \\
{[-0.0103,0.0173]}\end{array}$ \\
\hline Negative Affect & $\begin{array}{c}\mathbf{0 . 0 3 8 6} \\
{[0.0290,0.0483]}\end{array}$ & $\begin{array}{c}\mathbf{0 . 0 1 2 8} \\
{[0.0097,0.0159]}\end{array}$ & $\begin{array}{c}\mathbf{0 . 0 1 3 8} \\
{[0.0057,0.0218]}\end{array}$ & $\begin{array}{c}\mathbf{0 . 0 4 2 7} \\
{[0.0303,0.0552]}\end{array}$ \\
\hline Deactivation & $\begin{array}{c}\mathbf{0 . 0 1 7 9} \\
{[0.0094,0.0264]}\end{array}$ & $\begin{array}{c}\mathbf{0 . 0 0 4 1} \\
{[0.0012,0.0071]}\end{array}$ & $\begin{array}{c}0.0068 \\
{[-0.0014,0.0149]}\end{array}$ & $\begin{array}{c}\mathbf{0 . 0 2 5 0} \\
{[0.0158,0.0343]}\end{array}$ \\
\hline
\end{tabular}

Note. Table depicts means ( $95 \%$ confidence intervals in brackets). Bold values indicate means statistically significant larger than zero $(p<.05)$.

Note that couplings with negative affect and deactivation have been multiplied by -1 to facilitate interpretation; high values on all estimates correspond to a strong coupling in the hypothesized direction. 


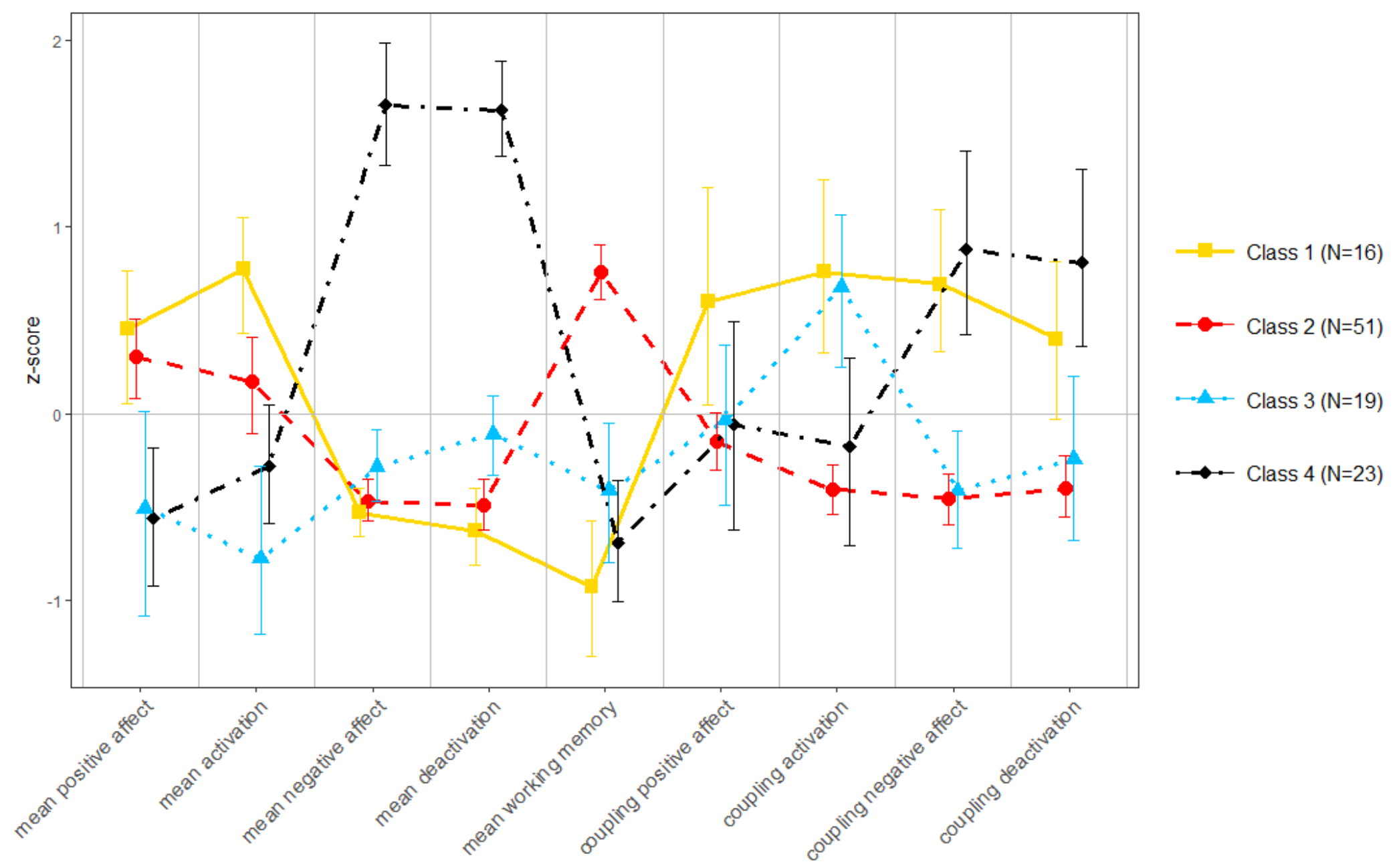

Figure 1. Figure depicts mean z-scores of the nine variables. Error bars indicate $95 \%$ bootstrap confidence intervals. Note that couplings with negative affect and deactivation have been multiplied by -1 to facilitate interpretation; high values on all estimates correspond to a strong coupling in the hypothesized direction. 

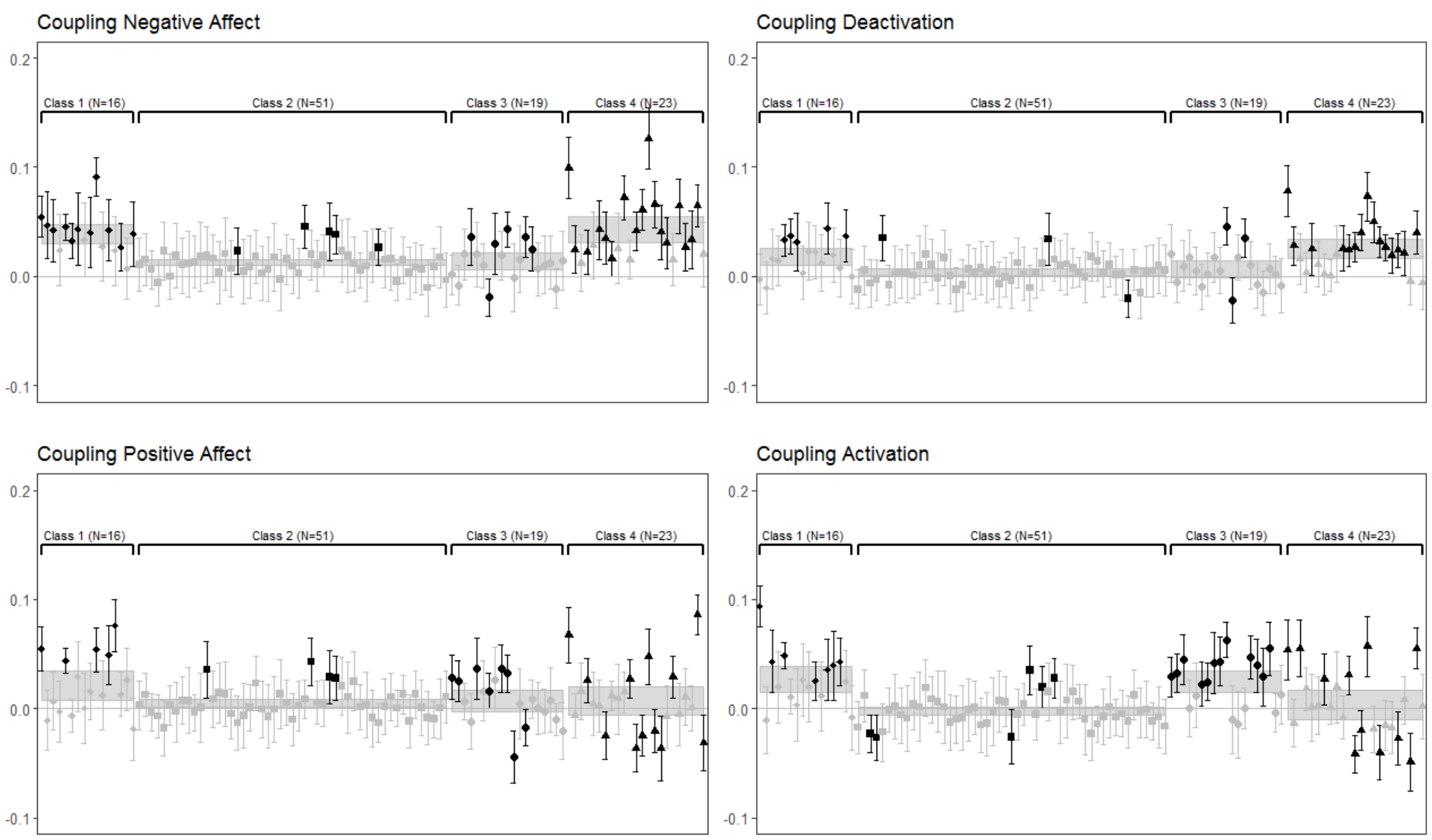

Figure 2. Figure depicts person-specific intra-individual couplings (see $\beta_{2 i}$ in Equation (4)); error bars indicate $+/-1$ standard error. Each symbol represents one child. Black symbols indicate that person specific intra-individual regression coefficients are at least one standard error larger / smaller than zero. Shaded grey areas depict $95 \%$ confidence intervals around the class mean. Note that couplings with negative affect and deactivation have been multiplied by -1 to facilitate interpretation; high values on all estimates correspond to a strong coupling in the hypothesized direction. 